\title{
FISIOLOGIA NA EDUCAÇÃO DE JOVENS PARA A CIDADANIA 1
}

\author{
Physiology in teenagers' education for citizenship
}

\author{
Ana Maria Caliman Filadelfi ${ }^{2}$ \\ Alessandra Amaral Schwanke ${ }^{3}$ \\ Fernanda Gabriela Leandro Schaedler ${ }^{2}$ \\ Isabelle Regina de Oliveira Ayres²
}

\begin{abstract}
RESUMO
O projeto visa ampliar a formação cidadã de jovens e consiste no planejamento, aplicação e avaliação de aulas (teóricas e práticas), abrangendo seis diferentes temas, todos estimulando o conhecimento e cuidado com o corpo humano (autocuidado). Estão entre eles: funções básicas do corpo humano, puberdade e Doenças Sexualmente Transmissíveis (DSTs), distúrbios alimentares, consumo de drogas, transtornos de humor, etc. Essas aulas são ministradas no Centro Alvorecer Ação Social e Educacional (CAASE), que tem como objetivo facilitar o acesso de jovens carentes ao mercado de trabalho, através de um Programa de Aprendizagem. Nosso projeto visa não somente contribuir para a formação dos jovens, mas também ampliar a formação das acadêmicas do curso de Enfermagem envolvidas, que participam do planejamento, confecção e aplicação das aulas. A capacitação dos funcionários-docentes do CAASE também entra como objetivo do projeto, uma vez que eles deverão poder continuar parte das atividades quando não for possível a participação dos docentes e alunos da Universidade Federal do Paraná (UFPR). Finalmente, a obtenção de dados sobre a avaliação do projeto feita pelos adolescentes, funcionários do CAASE e acadêmicas da UFPR, bem como sobre a situação de empregabilidade dos adolescentes vinculados soma-se a este artigo com o objetivo de ampliar a compreensão do alcance geral desta ação.
\end{abstract}

Palavras-chave: educação; fisiologia; adolescentes; cidadania; saúde.

\begin{abstract}
This project aims at fostering the sense of citizenship of teenagers. It consists of the planning, implementation and evaluation of theoretical and practical classes, including six different themes that stimulate the knowledge and care with the human body (selfcare). The treated themes were: The human body basic functions, puberty and Sexually Transmitted Diseases (STDs), eating disorders, use of drugs, mood disorders and others. The lessons were given at the Centro Alvorecer Ação Social e Educacional (CAASE) that intends to increase access of unprivileged teenagers to the job market through a learning program. Our project helps in the teenagers' education, but also aims at enriching the general formation of Nursery

\footnotetext{
${ }^{1}$ Agradecimentos: à Profa. Dra. Carolina A. O. Freire pela revisão do resumo em inglês e à Laísa Souza pela tradução do resumo para espanhol.

${ }^{2}$ Doutora e Mestre em Fisiologia pela USP; graduada em Ciências Biológicas pela USP; Professora de Fisiologia da UFPR; Departamento de Fisiologia, Setor de Ciências Biológicas, Universidade Federal do Paraná. E-mail: anamfila@ufpr.br

${ }^{3}$ Graduandas em Enfermagem; bolsistas - extensão 2011/2012 pela PROEC, UFPR.
}

FILADELFI, Ana M. C. et al. Fisiologia na educação de jovens para a cidadania. Extensão em Foco, Curitiba: Editora da UFPR, nr.9, jan/jun 2014, p.79-93. ISSN 2358-7180 
undergraduates of the Federal University of Paraná who receive scholarships and take part and help in the project (planning, implementation and development of the classes). The training of the CAASE educators is also a major goal of our project. They can continue with part of the activities in the future, although without the participation of UFPR members (professors or students). Finally, data obtained on evaluations of the project performed by the teenagers, CAASE educators and UFPR undergraduate students, as well as about how it was effective in improving the professional situation of the teenagers after their participation in the program were included here. These data contribute to increase the general reach of this action understanding.

Keywords: education; physiology; teenagers; citizenship; health.

\section{RESUMEN}

El proyecto tiene como objeto ampliar la formación de la ciudadanía de los jóvenes, a través de la planificación, aplicación y evaluación de clases (teórica y practicas), exponiendo seis distintos temas, todos ellos promoviendo el conocimiento y el respecto con el cuerpo humano (auto respecto). Son ellos: funciones básicas del cuerpo humano, adolescencia y enfermedades sexualmente transmisibles, disturbios alimentares, consumo de drogas, disturbios en el humor, etc. Esas clases son ministradas en el Centro Alvorecer Ação Social e Educacional (CAASE), que tiene como objeto facilitar el acceso de los jóvenes de las clases más bajas al mercado de trabajo, por medio de un Programa de Aprendizaje. Nuestro proyecto tiene como objeto no solamente contribuir para la formación de los jóvenes, sino también amplificar la de los estudiantes del curso de Enfermería involucradas, que participan del planeamiento, confección y aplicación de las clases. La capacitación de los funcionariosdocentes del CAASE también es parte del objeto de este proyecto, una vez que ellos deberán ser capaces de proseguir con las actividades cuando no sea posible la participación de los docentes y alumnos de la UFPR. Finalmente, la obtención de datos al respeto de la evaluación del proyecto hecha por los adolescentes, funcionarios del CAASE y alumnos de la UFPR, así como al respeto de la situación de empleo de los adolescentes vinculados sumase a este artículo con el objeto de amplificar la comprensión del alcance general de esta acción.

Palabras-clave: educación, fisiología, jóvenes, ciudadanía, salud.

\section{INTRODUÇÃO}

Os adolescentes encontram-se em uma fase de ampla busca de identidade, que passa pela escolha do papel sexual, profissional, dentre outros (BEE, 1984). Devido a isso, muitas vezes terminam por sucumbir a pressões dos grupos de amigos quanto ao uso de drogas ou iniciação precoce no campo sexual. Assim, informações que possam contribuir para a conscientização dos jovens sobre os riscos envolvidos em determinados comportamentos, podem previnir ou pelo menos conscientizá-los sobre as consequências de adoção destes, desmistificando, ainda, estereótipos e atitudes preconceituosas (CRUZ; OLIVEIRA, 2002; FAUSTINE et al., 2003). Neste sentido, é sabido que uma série de ações sociais têm contribuído para retirar jovens das ruas e transformar sua realidade através da arte, dos esportes e da educação (ANDRÉ; COSTA, 2004; PAPALIA; OLDS, 2000).

FILADELFI, Ana M. C. et al. Fisiologia na educação de jovens para a cidadania. Extensão em Foco, Curitiba: Editora da UFPR, nr.9, jan/jun 2014, p.79-93. ISSN 2358-7180 
O projeto tem como instituição parceira o Centro Alvorecer Ação Social e Educacional (CAASE), o qual tem duas unidades na cidade de Curitiba (PR): uma no Bairro Alto (o "Lar Fabiano de Cristo", situado à Rua Pedro Elói de Souza, 1141) e outra no Cajuru ("Polo Joana D'arc", situado à Rua Assis de Brito, 30), esta última criada recentemente a partir de um assentamento local. A instituição realiza um amplo programa de promoção social, atendendo centenas de pessoas por ano, cujo objetivo é reerguer socialmente famílias carentes, ajudando, inclusive, a inserir jovens no mercado de trabalho em serviços compatíveis com a sua faixa etária e formação escolar. Esta última ação é feita através do desenvolvimento de um Programa de Aprendizagem (Lei 10.097/2000) cujo objetivo, neste caso, é formar assistentes administrativos para atuar em empresas diversas. Neste programa, os adolescentes ficam dois anos vinculados ao CAASE e cumprem 24 horas-aula semanais nesta instituição e mais 16 horas-semanais na empresa à qual se vincularem no início do programa. No CAASE, além de uma grade curricular básica exigida pela legislação, os adolescentes são estimulados a desenvolver a cidadania, a responsabilidade, a ética, a autoestima, a convivência em grupo, o respeito pelo outro, a cuidar do asseio, etc.

A ideia deste projeto de extensão, "Fisiologia na educação de jovens para a cidadania", surgiu a partir do curso de extensão "Transformando pela educação: a Fisiologia contribuindo na formação extracurricular do adolescente", o qual já foi realizado por dois anos consecutivos (2009 e 2010 - sob aprovação da PROECUFPR) na mesma instituição parceira e teve bastante aceitação da direção e, principalmente, dos adolescentes que participaram. Como a instituição renova as famílias assistidas, sempre há a demanda de diferentes jovens provenientes de novas famílias.

Assim, o projeto, tal como o curso, visa contribuir no programa de inserção social-profissional desses jovens, desenvolvendo temas na área de Biologia e Saúde. Acredita-se que levar ao adolescente uma consciência maior sobre os processos fisiológicos de seu corpo e sobre questões sociais e de saúde relevantes, tais como, a prevenção das Doenças Sexualmente Transmissíveis (DSTs), os distúrbios alimentares, o consumo de drogas, dentre outros, pode torná-los cidadãos mais capazes de fazer escolhas melhores para suas vidas (ANDRÉ; COSTA, 2004; 
CARVALHO, 2003; PAPALIA; OLDS, 2000). Como muitas vezes esses assuntos são precariamente tratados nas escolas públicas (ASINELLI-LUZ, 2008), às quais os adolescentes vindos de famílias de baixa-renda costumam ter acesso, esta iniciativa pretende suprir parte desta necessidade de conscientização. Outro aspecto relacionado é que a certificação obtida pelos adolescentes pode compor o seu currículo profissional somando-se ao objetivo do Programa de Aprendizagem da instituição de melhorar a inserção destes no mercado de trabalho.

No entanto, além de transmitir informações que contribuam na formação dos jovens cidadãos, o projeto teve seus objetivos ampliados em relação ao curso por envolver alunas da UFPR e, mais diretamente, os funcionários-docentes da instituição.

As alunas da universidade em questão são acadêmicas do curso de Enfermagem, e tiveram a possibilidade de conviver com diferentes públicos (funcionários-docentes da instituição e adolescentes) e de desenvolver a habilidade de comunicação dos conceitos da área de Saúde para eles. As discentes estiveram envolvidas em todas as etapas do projeto, conforme descrito na Metodologia deste artigo e a participação nas aulas e a interação com a comunidade propiciou a elas, além de um treinamento didático, a vivência de situações extraclasse enriquecedoras de sua formação como universitárias, enfermeiras e cidadãs.

O projeto pretende capacitar também os funcionários-docentes do CAASE (em suas duas unidades) para manter ao menos parte das atividades nos anos subsequentes, mesmo que não seja possível a participação da universidade, ou seja, atuando também com o foco na transformação da realidade social existente na própria instituição parceira. Neste sentido, tais funcionários passaram por um treinamento didático (envolvendo os temas de Biologia e Saúde em questão) e puderam praticar a habilidade adquirida ministrando, sob supervisão da docente e alunas da UFPR, parte das aulas aos adolescentes que participam do projeto social da instituição. A ideia é, então, transformar a realidade local no sentido de permitir que as aulas continuem acontecendo futuramente mesmo sem a participação da UFPR.

Considerando-se a universidade como uma instituição educacional, vislumbramos nesta iniciativa uma forma de tornar compatível as atividades de ensino, assistencialismo e cidadania, no sentido de que os(as) acadêmicos(as) da UFPR

FILADELFI, Ana M. C. et al. Fisiologia na educação de jovens para a cidadania. Extensão em Foco, Curitiba: Editora da UFPR, nr.9, jan/jun 2014, p.79-93. ISSN 2358-7180 
envolvidos(as) possam tornar-se sensíveis às necessidades da sociedade e, com isso, adquirirem um maior comprometimento social em suas futuras ações profissionais. Mais ainda, a interação dos membros da UFPR (docente e acadêmicas) com os profissionais e adolescentes vinculados ao CAASE, permite uma ampla troca de conhecimentos, valores e saberes compondo de maneira extremamente válida o princípio de interação dialógica ou interação participativa (ROSELLI-CRUZ, 1989) tão intrínseco à prática da extensão.

A partir dos temas de aula descritos no item Metodologia (p. ex, "O corpo humano" X "O adolescente na família, na escola e na sociedade"), e que ainda deverão ser ampliados para os anos seguintes, também pretendemos que o projeto contemple a questão da interdisciplinaridade, visto que este também é um importante princípio da prática da extensão universitária.

Finalmente, o acompanhamento, até onde é possível, das taxas de inserção no mercado de trabalho dos jovens vinculados ao projeto e aos cursos de 2009 e 2010, permite a obtenção de alguns dados que se aproximam do caráter de uma pesquisa, os quais estão sendo divulgados no presente artigo a fim de garantir a indissociabilidade entre ensino-pesquisa-extensão.

\section{OBJETIVOS}

O projeto de extensão tem como objetivos:

1. Ampliar o conhecimento, o respeito e o cuidado dos adolescentes vinculados ao CAASE com o seu próprio corpo. Isso se dá especialmente nas aulas práticas, em que eles vivenciam os temas abordados.

2. Esperando uma continuidade do projeto, é realizada simultaneamente a capacitação dos educadores da instituição. Para que isto aconteça, estes passam por um treinamento que consiste em assistir a mesma aula ministrada aos alunos, porém em um momento anterior. Posteriormente são convidados a colaborar nas aulas dos adolescentes, contribuindo com conhecimento de sua área de formação.

3. A vivência acadêmica das alunas da UFPR acontece por meio da preparação prévia do material didático, além da participação durante a exposição das aulas, processamento de avaliações e dados obtidos, confecção de relatórios, etc. Como 
os temas são voltados à área da saúde, as graduandas apresentam facilidade em discorrer sobre os assuntos dentro e fora do espaço onde o projeto é desenvolvido.

4. Levando em consideração que a extensão disponibiliza um certificado para os concluintes e que a instituição tem como objetivo inserir os adolescentes no mercado de trabalho, o projeto anseia também realizar um acompanhamento póscurso, efetuando uma mensuração possível desta inserção. Além disso, é realizada uma coleta de opiniões dos adolescentes, educadores e acadêmicas para que seja possível efetuar alterações necessárias tanto nas aulas teóricas, quanto nas aulas práticas para a continuidade do projeto.

\section{METODOLOGIA}

As aulas acontecem nas duas unidades do CAASE, durante o contra turno escolar dos adolescentes. A linha pedagógica adotada apoia-se na abordagem construtivista. As aulas teóricas são expositivas, dialogadas com auxílio de slides, livros, apostilas e outros materiais de apoio. Nas aulas práticas são utilizados jogos didáticos, dinâmicas, vídeos, colagens etc. Após cada aula é realizada uma pequena avaliação do conteúdo abordado, possibilitando alterações de acordo com a necessidade. Por dia de encontro, o total de tempo de atividades (teórica + prática + avaliação) leva cerca de duas horas.

Os temas trabalhados são: O Corpo Humano; Puberdade, Hormônios e Reprodução; DSTs e Métodos Anticoncepcionais; Depressão e transtornos alimentares; Drogas e seus efeitos; O adolescente na escola, na família e na sociedade. Além disso, são realizados dois encontros extras para uma avaliação parcial (após a terceira aula) e final (após a última) a fim de se obter a opinião dos alunos a respeito dos temas abordados e esclarecer possíveis dúvidas.

Em resumo, as atividades dos adolescentes incluem a participação nas aulas e suas avaliações (preenchimento de roteiros de atividades), incluindo aquelas referentes à avaliação/discussão parcial e final. Somente são considerados aprovados, os adolescentes que obtêm média final de 60 (de 0 a 100) e $80 \%$ de frequência, sendo que estes recebem o certificado de participação que pode ser incluído em seu currículo.

FILADELFI, Ana M. C. et al. Fisiologia na educação de jovens para a cidadania. Extensão em Foco, Curitiba: Editora da UFPR, nr.9, jan/jun 2014, p.79-93. ISSN 2358-7180 
Os educadores também respondem, previamente, aos mesmos roteiros de atividades que os adolescentes, bem como contribuem continuamente e nos dias de avaliação parcial e final com opiniões, sugestões e discussões sobre as aulas. Além disso, preparam as partes das aulas dos adolescentes, em que têm atuação mais direta, e recebem orientação e um retorno da coordenadora sobre sua atuação durante tais aulas. $O$ critério de notas para receberem o certificado de participação é o mesmo dos adolescentes.

As acadêmicas de Enfermagem da UFPR, bolsistas do projeto, passam por um processo de orientação e avaliação contínua, colaborando em todas as etapas, desde o planejamento, a elaboração e a aplicação do material didático e das aulas, até o treinamento dos funcionários-docentes, a elaboração e a correção das avaliações de docentes e adolescentes, a análise e a discussão dos objetivos e resultados (notas, participação, interesse) alcançados com a ação, bem como a elaboração do relatório anual/final, deste artigo, e de cartilhas didáticas que estão ainda em preparação.

\section{RESULTADOS}

\section{Desempenho dos adolescentes e educadores no projeto:}

Imagens dos adolescentes (FIGURA 1), educadores e coordenadoras (FIGURA 2) e bolsistas extensão (FIGURA 3) durante as atividades do projeto.

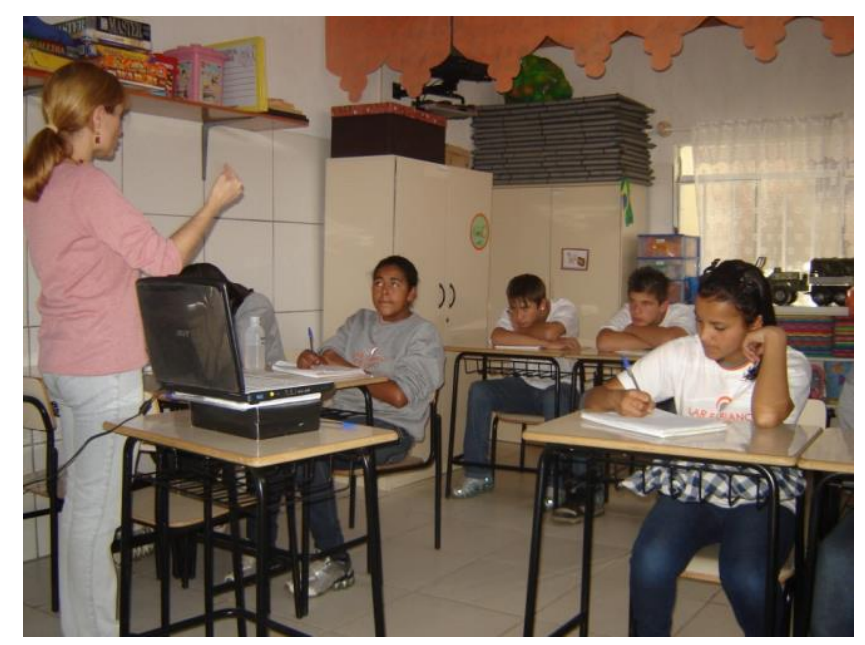

FIGURA 1 - Adolescentes durante aula vinculada ao projeto de extensão "Fisiologia na educação de jovens para a cidadania" - 2011, na unidade Cajuru do CAASE.

FILADELFI, Ana M. C. et al. Fisiologia na educação de jovens para a cidadania. Extensão em Foco, Curitiba: Editora da UFPR, nr.9, jan/jun 2014, p.79-93. ISSN 2358-7180 


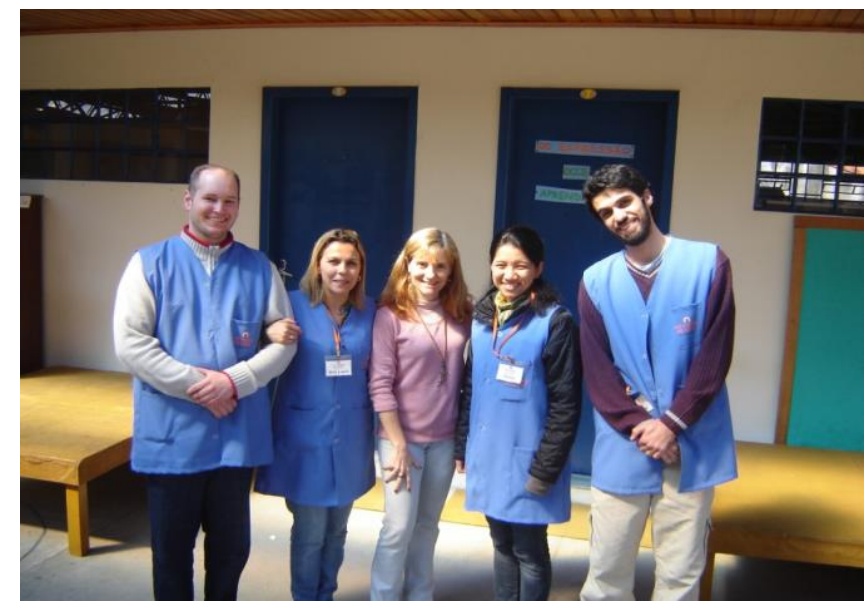

FIGURA 2 - Educadores e coordenadoras (do projeto e do CAASE) em pátio da instituição no Bairro Alto após treinamento didático vinculado ao projeto de extensão "Fisiologia na educação de jovens para a cidadania" - 2011.

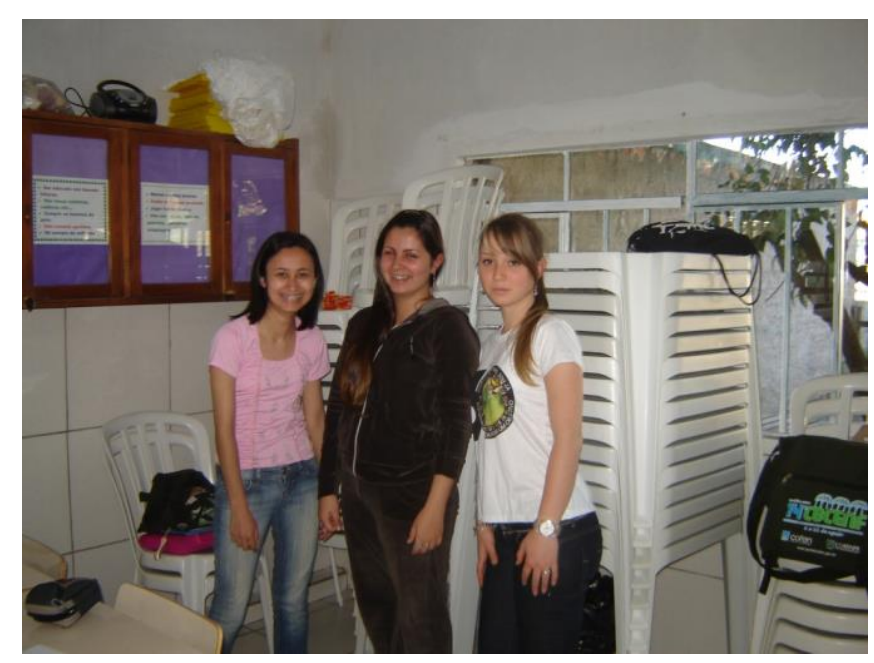

FIGURA 3 - Alunas bolsistas de enfermagem da UFPR, em intervalo de aula na unidade Cajuru do CAASE, durante as atividades do projeto de extensão "Fisiologia na educação de jovens para a cidadania" - 2011.

Dos adolescentes participantes do projeto de extensão de 2011, 57\% foram aprovados no curso vinculado ao projeto e 43\% foram reprovados (FIGURA 4). Em números absolutos, foram 13 adolescentes aprovados em um total de 20 . Este total inclui as duas turmas com que trabalhamos referentes às duas unidades da instituição: Bairro Alto e Cajuru. Os aprovados estão aptos a receber o certificado de participação 
no projeto/curso emitido pela Pró-reitoria de Cultura e Extensão da UFPR (PROECUFPR).

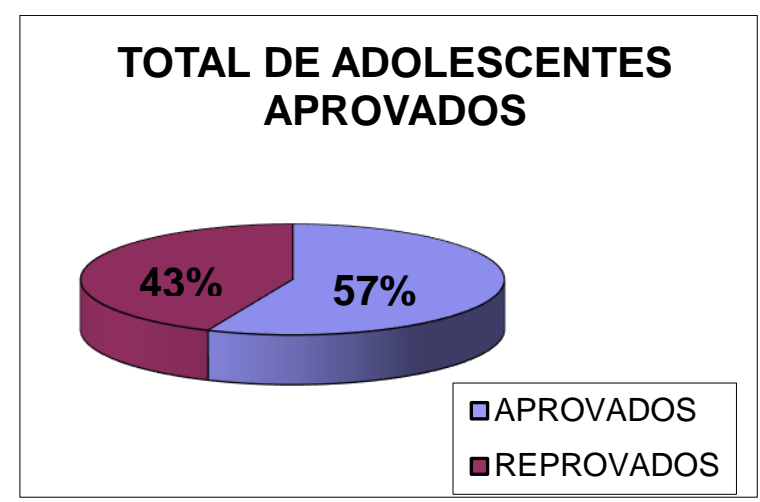

FIGURA 4 - Total de adolescentes participantes do programa de aprendiz do CAASE aprovados no curso vinculado ao projeto de extensão "Fisiologia na educação de jovens para a cidadania" - 2011.

Com relação aos educadores do CAASE que participaram do treinamento oferecido ao longo do projeto de extensão, de seis educadores, quatro foram aprovados, ou seja: $67 \%$ aprovados e $33 \%$ reprovados (FIGURA 5). Os dois educadores reprovados, na realidade, saíram da instituição (CAASE) e, portanto, não concluíram a participação no projeto. Os aprovados, novamente, estão aptos a receber o certificado de participação no projeto/curso emitido pela PROEC-UFPR.

Todos os educadores que participaram das ações de extensão receberam os materiais didáticos visuais produzidos ao longo do projeto e foram orientados no sentido de usos futuros desses materiais em aula com os adolescentes.

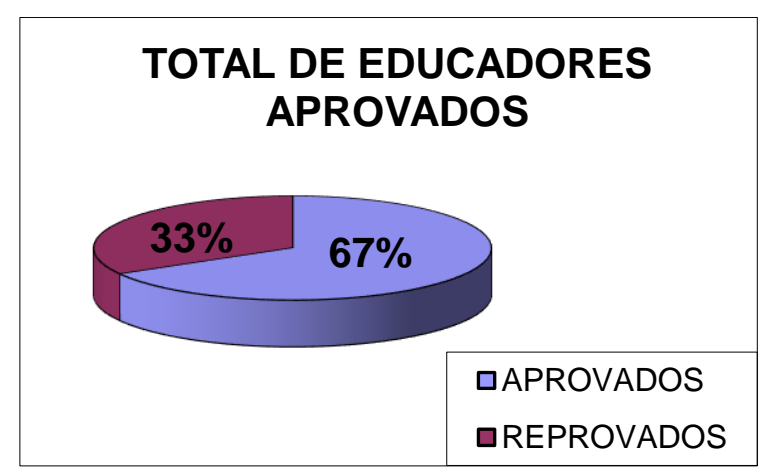

FILADELFI, Ana M. C. et al. Fisiologia na educação de jovens para a cidadania. Extensão em Foco, Curitiba: Editora da UFPR, nr.9, jan/jun 2014, p.79-93. ISSN 2358-7180 
FIGURA 5 - Total de educadores participantes do programa de aprendiz do CAASE aprovados no curso/treinamento vinculado ao projeto de extensão "Fisiologia na educação de jovens para a cidadania" - 2011.

\section{Destino dos adolescentes do CAASE em relação ao mercado de trabalho:}

As iniciativas de extensão vinculadas ao CAASE começaram em 2009. Em 2009 e 2010 foram realizados, respectivamente, dois cursos de extensão e agora, em 2011, o projeto em questão.

Os dados abaixo ilustram o destino dos adolescentes que passaram pelo programa de aprendizes do CAASE em 2008, 2009, 2010 e 2011, com relação à sua vinculação com o mercado de trabalho, a qual é o objetivo principal deste programa.

A turma que concluiu o programa em 2008 teve apenas $40 \%$ dos adolescentes contratados por empresas diversas como auxiliares administrativos. 32\% dos adolescentes desistiram de participar do programa por motivos diversos e $28 \%$ tiveram baixo desempenho no CAASE ou na empresa e foram desligados do programa (FIGURA 6). Ou seja, nesta turma, anterior às iniciativas de extensão da UFPR no CAASE, menos da metade dos adolescentes conseguiu sua vinculação ao mercado de trabalho até aonde é de nosso conhecimento.

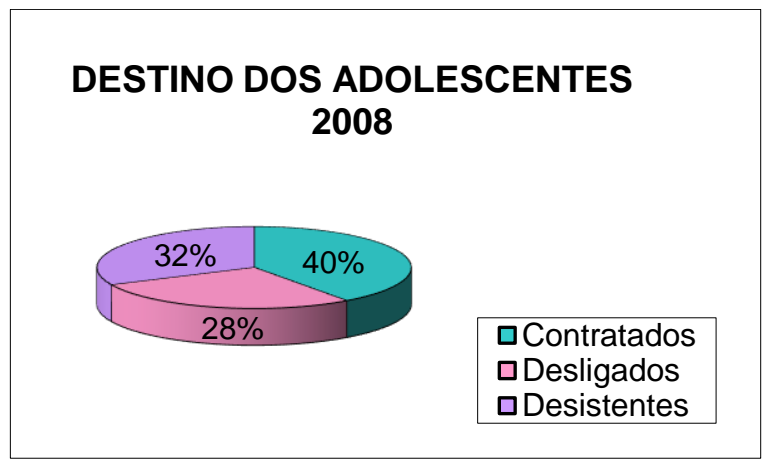

FIGURA 6 - Destino dos adolescentes do CAASE que concluíram o programa de aprendizes em 2008, em relação à sua inserção no mercado de trabalho.

Em 2009, quando iniciamos o primeiro curso de extensão, a turma que concluiu o programa de aprendizes do CAASE apresentou os seguintes destinos: $52 \%$ foram contratados por empresas diversas como auxiliares administrativos; $32 \%$ dos 
adolescentes desistiram de participar do programa por motivos diversos e apenas $16 \%$ tiveram baixo desempenho no CAASE ou na empresa e, consequentemente, foram desligados do programa (FIGURA 7). A partir desses dados verifica-se uma pequena melhora de desempenho em relação àqueles adolescentes da turma de 2008.

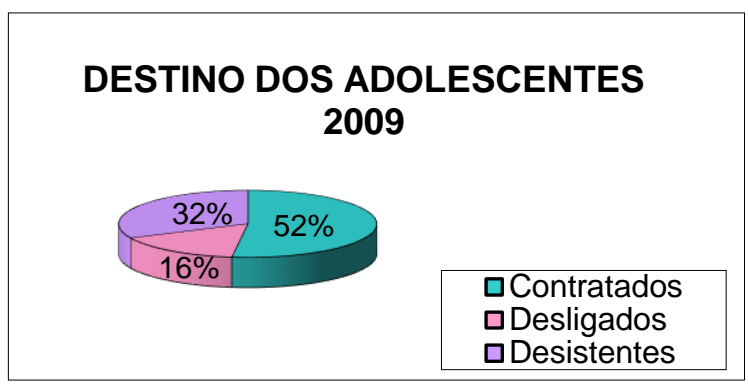

FIGURA 7 - Destino dos adolescentes do CAASE que concluíram o programa de aprendizes em 2009 e participaram do curso de extensão "Transformando pela educação: a Fisiologia contribuindo na formação extracurricular do adolescente" em 2009, em relação à sua inserção no mercado de trabalho.

Dos adolescentes que foram aprovados no curso de extensão de 2010 e no projeto de 2011, 100\% está efetivamente vinculado a alguma empresa como aprendiz (FIGURA 8). Essa vinculação não é ainda uma contratação pela empresa, já que essas turmas ainda estão cursando o programa de aprendiz, mas indica que o desempenho dos jovens está sendo adequado tanto no CAASE como na empresa, para que esta queira mantê-los como aprendizes, o que pode gerar uma contratação futura.

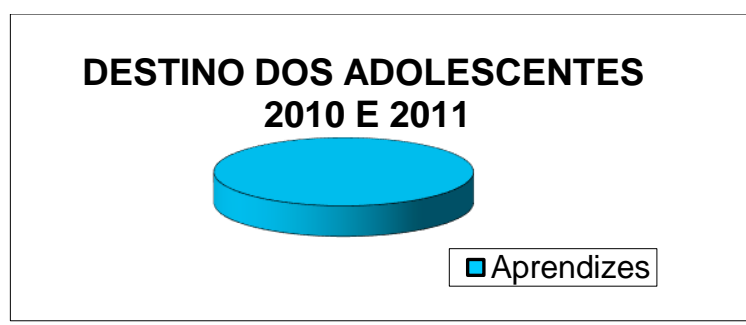

FIGURA 8 - Destino dos adolescentes do CAASE que estão cursando o programa de aprendizes do CAASE e participaram do curso de extensão "Transformando pela educação: a Fisiologia contribuindo na formação extracurricular do adolescente" em

FILADELFI, Ana M. C. et al. Fisiologia na educação de jovens para a cidadania. Extensão em Foco, Curitiba: Editora da UFPR, nr.9, jan/jun 2014, p.79-93. ISSN 2358-7180 
2010 ou do projeto de extensão "Fisiologia na educação de jovens para a cidadania" em 2011, em relação à sua inserção no mercado de trabalho.

Assim, podemos sugerir que as iniciativas de extensão estejam de alguma forma contribuindo com essa possibilidade de inserção dos adolescentes no mercado de trabalho, até mesmo porque os certificados do curso ou projeto de extensão, obtidos pelos adolescentes, podem ser anexados ao seu curriculum vitae. Além disso, os conhecimentos de Biologia e saúde trabalhados nas aulas do curso/projeto podem auxiliar os adolescentes também em seu ensino regular e isto novamente pode contribuir para que se vinculem com mais facilidade ao mercado de trabalho.

\section{Preferência dos adolescentes quanto às atividades realizadas no projeto:}

Foram desenvolvidos seis temas de aulas teóricas e práticas com os adolescentes, a saber: (1) O corpo humano; (2) Puberdade, hormônios e reprodução; (3) DSTs e métodos anticoncepcionais; (4) Depressão e transtornos alimentares; (5) Drogas e seus principais efeitos e (6) $O$ adolescente na escola, na família e na sociedade.

Os dados abaixo representam as preferências dos adolescentes com relação a estes. Assim, nos gráficos consta a porcentagem dos adolescentes que escolheu 0 tema de cada aula em primeiro, segundo, terceiro, quarto, quinto ou sexto lugar de preferência. São apresentados dados separados para as aulas teóricas (FIGURA 9) e as práticas (FIGURA 10).

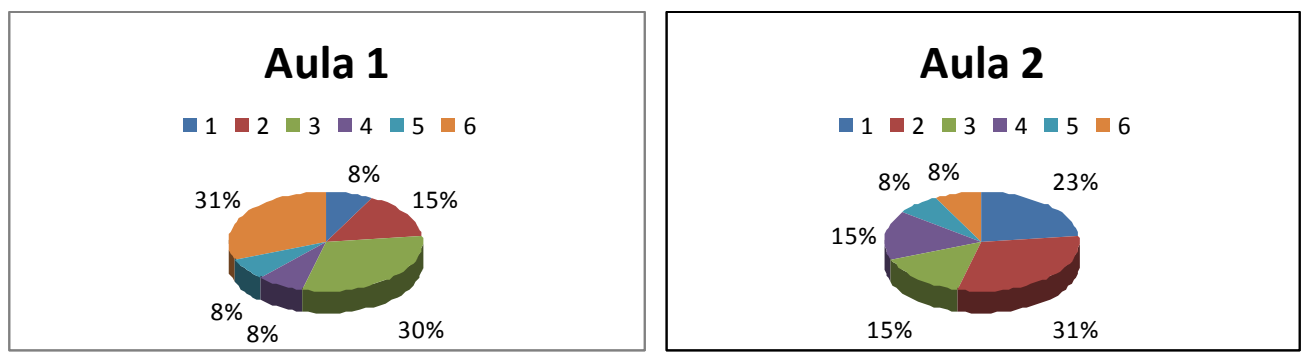

FILADELFI, Ana M. C. et al. Fisiologia na educação de jovens para a cidadania. Extensão em Foco, Curitiba: Editora da UFPR, nr.9, jan/jun 2014, p.79-93. ISSN 2358-7180 

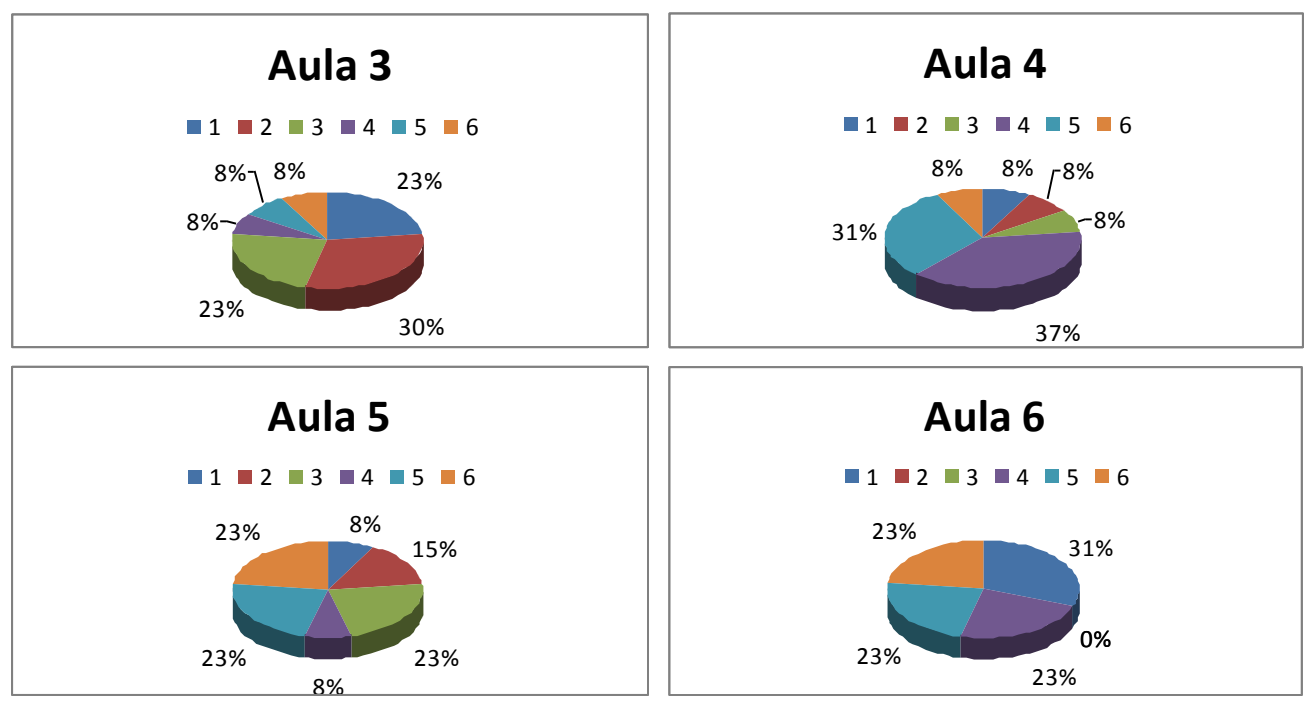

FIGURA 9 - Ordem de preferência pelas aulas teóricas de 1ํㅡㄴ 6ํำ pelos adolescentes das turmas do Bairro Alto e Cajuru do CAASE.
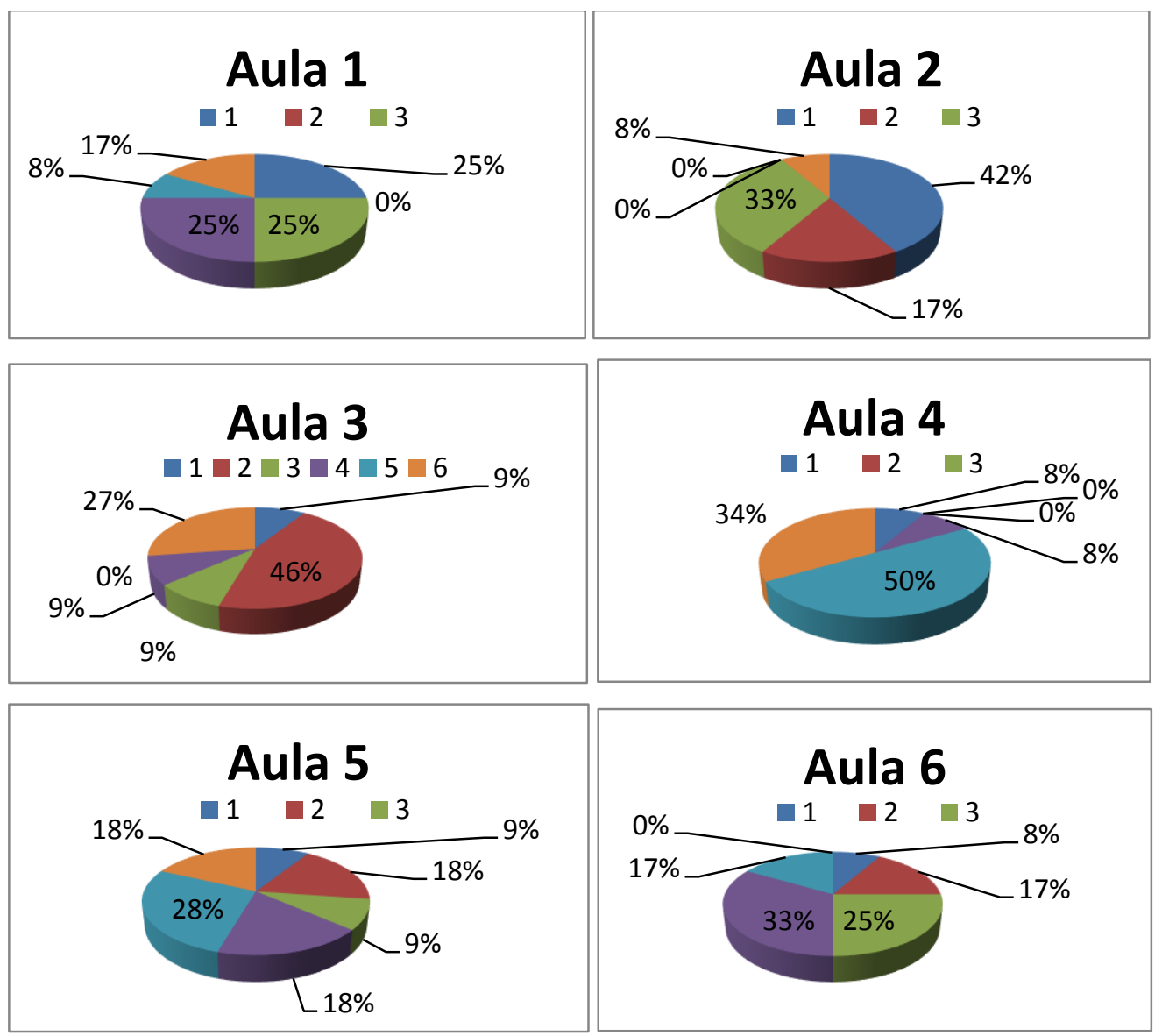

FIGURA 10 - Ordem de preferência pelas atividades de aulas práticas (referentes a cada aula teórica) de 1ํ a 6º pelos adolescentes das turmas do Bairro Alto e Cajuru do CAASE.

FILADELFI, Ana M. C. et al. Fisiologia na educação de jovens para a cidadania. Extensão em Foco, Curitiba: Editora da UFPR, nr.9, jan/jun 2014, p.79-93. ISSN 2358-7180 
Pelos dados apresentados, verificamos que as preferências foram bastante variadas, mas, de maneira geral, para as aulas teóricas (FIGURA 9) considerando-se as votações de $1^{\circ}, 2^{\circ}$ e $3^{\circ}$ lugares, as aulas 1, 2, 3 e 6 tem metade ou mais do gráfico de pizza ocupado com as primeiras colocações, enquanto as aulas 4 e 5 foram as menos bem aceitas. Realmente, os temas dessas duas últimas aulas (Depressão e transtornos alimentares e Drogas e seus principais efeitos) são temas difíceis, embora, ainda acreditamos, necessários para os adolescentes.

Com relação às atividades de aulas práticas (FIGURA 10), novamente as das aulas 1, 2, 3 e 6 tem metade ou mais do gráfico de pizza ocupado com as primeiras colocações, enquanto as aulas 4 e 5 foram as menos bem aceitas. Porém, neste caso, chega a haver um destaque para as atividades das aulas 2 e 3 em preferência dos adolescentes. Essas atividades foram, respectivamente, um jogo de tabuleiros sobre reprodução humana e uma dinâmica interativa sobre DSTs, ambas dinâmicas, divertidas, exigindo a participação de todo o grupo, além de testando a atenção e o conhecimento adquiridos durante a aula. As menos preferidas (aulas 4 e 5), talvez por terem exigido participação mais restrita dos adolescentes, foram uma atividade de recorte e colagem sobre Depressão e Transtornos alimentares e a exibição de um vídeo sobre drogas reproduzido de um programa de televisão aberta. Estaremos reformulando estas atividades para novas versões do projeto. Por outro lado, pôde-se observar uma razoável coerência entre as preferências de aulas teóricas e atividades práticas.

Para a continuidade do projeto de extensão e seu curso vinculado, estaremos ainda ampliando os temas de aulas e deixando os que já existiam ainda mais dinâmicos, para melhorar o interesse dos adolescentes por eles. Para tanto, diversas atividades entre dinâmicas, jogos, vídeos etc., serão incluídas na parte prática das aulas e estas serão mais mescladas com a parte teórica.

\section{CONCLUSÕES}

1. As atividades de extensão parecem contribuir na formação cidadã dos adolescentes envolvidos e na sua vinculação com o mercado de trabalho

FILADELFI, Ana M. C. et al. Fisiologia na educação de jovens para a cidadania. Extensão em Foco, Curitiba: Editora da UFPR, nr.9, jan/jun 2014, p.79-93. ISSN 2358-7180 
relativo às empresas associadas ao Programa do Aprendiz da instituição CAASE.

2. Percebe-se uma preferência dos adolescentes por temas de aulas mais leves e de fácil discussão e por atividades práticas altamente dinâmicas como jogos e dinâmicas interativas.

3. A associação entre a formação para o mercado de trabalho desenvolvida pelo CAASE, e o conhecimento sobre o corpo humano e suas funções, transmitido pelo projeto em questão, parecem resultar em valorização do adolescente em relação a si mesmo e ao próximo, tornando-o, simultaneamente, melhor capacitado para atuar na vida profissional.

\section{REFERÊNCIAS}

ANDRÉ, Simone; COSTA, Antonio Carlos Gomes da. Educação para o desenvolvimento humano. São Paulo: Saraiva: Instituto Ayrton Senna, 2004.

ASINELLI-LUZ, A. A extensão universitária enquanto fonte de conhecimento nos temas drogas, gênero e sexualidade. Extensão em foco, Curitiba, n. 1, p. 89-96, jan./jun. 2008.

BEE, Hellen. A criança em desenvolvimento. São Paulo: Harbra-Harper \& Row do Brasil, 1984.

CARVALHO, A.; SALLES, F.; GUIMARÃES, M. (Orgs). Adolescência. Belo Horizonte: Ed. UFMG, 2003.

CRUZ, A. C. N.; OLIVEIRA, S. M. P. Sexualidade do adolescente: um novo olhar sem mitos e preconceito. Trabalho de conclusão de curso (Graduação) - Universidade da Amazônia, Belém, 2002.

FAUSTINE, D. M. T.; NOVO, N. F.; CURY, M. C. S. F.; JULIANO, Y. Programa de orientação desenvolvido com adolescentes em centro de saúde: conhecimentos adquiridos sobre os temas abordados por uma equipe multidisciplinar. Ciênc. Saúde Coletiva, São Paulo, v. 8, n. 3, 2003.

PAPALIA, Diane E.; OLDS, Sally Wendokos. Desenvolvimento humano. 7. ed. Porto Alegre: Artmed, 2000. 684 p.

ROSELLI-CRUZ, Amadeu. Prevenção do abuso de drogas como atividade de extensão universitária. Ciência às 6 e meia, Curitiba, v. 1, p. 43-49, 1989.

FILADELFI, Ana M. C. et al. Fisiologia na educação de jovens para a cidadania. Extensão em Foco, Curitiba: Editora da UFPR, nr.9, jan/jun 2014, p.79-93. ISSN 2358-7180 